\title{
Perspectives of the public on reducing population salt intake in Ireland
}

\author{
Áine Regan ${ }^{1, *}$, Christine Liran Shan ${ }^{1}$, Patrick Wall ${ }^{1}$ and Áine McConnon ${ }^{2}$ \\ ${ }^{1}$ School of Public Health, Physiotherapy, \& Population Science, University College Dublin, Belfield, Dublin 4, Republic \\ of Ireland: ${ }^{2}$ Avila Research, Dublin, Republic of Ireland
}

Submitted 12 April 2015: Final revision received 8 July 2015: Accepted 24 July 2015: First published online 2 September 2015

\begin{abstract}
Objective: As countries struggle to meet the set targets for population salt intake, there have been calls for more regulated approaches to reducing dietary salt intake. However, little is known about how the public perceives various salt reduction policies; an important line of investigation given that the implementation and success of these policies often depend on public sentiment. We investigated the attitudes and beliefs of consumers towards salt reduction and their support for thirteen different government-led salt reduction policies.

Design: A cross-sectional online survey measured participants' knowledge, beliefs and attitudes in relation to salt reduction.

Setting: The survey was carried out with participants from the Republic of Ireland. Subjects: Five hundred and one participants recruited via a market research agency completed the survey.

Results: We found that the vast majority of participants supported eleven of the government-led salt reduction policies, which included measures such as education, labelling and salt restriction in foods (both voluntary and regulated, across a range of settings). The two proposed fiscal policies (subsidising low-salt foods and taxing high-salt foods) received less support in comparison, with the majority of participants opposed to a tax on high-salt foods. A series of multiple regressions revealed that individual attitudes and beliefs related to health and salt were stronger predictors of support than sociodemographic factors, lifestyle or knowledge.

Conclusions: The study provides an important evidence base from which policy makers may draw when making decisions on future policy steps to help achieve national salt targets.
\end{abstract} Keywords
Salt reduction
Government
Health policy
Public opinion
The relationship between dietary sodium (most commonly found in the form of salt), hypertension and subsequent risk for CVD has been well established ${ }^{(1,2)}$. The $\mathrm{WHO}^{(3)}$ set a target of $5 \mathrm{~g}$ salt/d for individuals and substantial action has been taken at the individual country level to implement measures to reduce salt intake and achieve set targets. In the current study, we investigate the views of the public towards government-led policies aimed at reducing population salt intake. An assessment of public sentiment towards health policies is critical as even the most well intentioned and well-crafted policy may flounder in the absence of public support ${ }^{(4)}$.

A large amount of the salt consumed within the population comes from processed foods ${ }^{(5)}$. For this reason, rather than promoting individual behavioural interventions, many argue that the emphasis needs to be placed on government-led 'upstream measures', with much attention on garnering commitments from the food industry to reduce salt content in processed foods ${ }^{(6-8)}$. A national salt reduction programme initiated in Ireland in $2003^{(9)}$ has strived to achieve gradual and sustained reductions in the salt content of processed and prepared foods through voluntary product reformulation efforts by the food industry, along with the development of salt reduction targets for specific products, monitoring salt levels in key foods and publishing industry progress and commitments. Other elements of the programme include working with the food industry to bring about universal labelling of salt in packaged foods and working with other state bodies to increase consumer understanding of salt and health. The Irish authorities have set what they consider an achievable population-level objective of $6 \mathrm{~g}$ salt/d. Substantial reductions have been made in the salt content of particular foods in Ireland ${ }^{(8)}$; however, population-level estimates 
are well in excess of the current target. The average mean intake among adults in Ireland in 2007 was found to be $9.3 \mathrm{~g} / \mathrm{d}$, with a significant gender difference; males had an intake of $10.4 \mathrm{~g} / \mathrm{d}$ and females an intake of $7.4 \mathrm{~g} / \mathrm{d}^{(10)}$. As such, there have been calls for a stricter, more regulated approach to salt reduction in Ireland ${ }^{(10)}$. There is little known about how the public may react to stricter salt reduction policies implemented by the government, despite public sentiment having a significant bearing on any future course of action. Furthermore, although studies have measured levels of salt intake among the Irish population ${ }^{(10)}$ and have investigated the specific health benefits of reducing salt intake among the Irish population $^{(7,11)}$, there has been a scarcity of research investigating the attitudes and beliefs of the Irish public in relation to salt intake and reduction. Investigating consumers' understanding of salt reduction can help to better target campaigns and salt reduction policies ${ }^{(5)}$. The current study aims to fill this gap by exploring the perceptions of Irish consumers towards salt reduction and their attitudes towards government-led salt reduction policies.

Public support of population-level interventions may not only impact the success of implementation, but stakeholders and politicians can be reluctant to intervene without support ${ }^{(12,13)}$. There have been investigations of public support for health behaviour policies (e.g. alcohol and tobacco use, diet and physical activity; see Diepeveen et $a l^{(13)}$ for a comprehensive review) and healthy eating policies ${ }^{(4,14)}$. However, there has been little investigation specifically focused on public attitudes of salt reduction policies, despite the existence of and strong emphasis placed on government-led salt reduction programmes worldwide $^{(15)}$. Drawing from the broader literature, there is evidence to suggest that support differs across policies and within the population.

There is strong evidence that the public tends to be most supportive of those health policies that are the least intrusive or restrictive and those that target children, and is less supportive of taxation or sales restrictions ${ }^{(13)}$. A study investigating the Irish public's attitudes towards obesity prevention policies found majority support for almost all of the policies, although the highest support tended to be for child-focused policies and informational policies, while the least support was found for those policies that could be viewed to be restricting personal choice ${ }^{(14)}$. However, even where less support for more paternalistic policies is reported, support levels still remain quite high ${ }^{(4)}$. One of the few studies investigating public support for various types of salt reduction policies was a survey of Canadians that found strong support for a range of policies targeting public education and the food environment, with the exception of those policies targeting food taxation and subsidisation $^{(16)}$. That study did not examine potential drivers of support.

Apart from the somewhat consistent evidence that older individuals are more supportive of policies ${ }^{(13,15)}$, overall, sociodemographic factors have been found to be poor predictors that explain little of the variance in public support $^{(4,14)}$. Research investigating public attitudes to healthy eating policies across five countries in the European Union found that compared with sociodemographic factors, predictive models that included behavioural and attitudinal/perceptual factors explained more variance in public support ${ }^{(4)}$. For example, beliefs regarding blame and responsibility for a public health issue have been found to be strong drivers of public acceptance ${ }^{(4,12)}$. In considering how attributions of responsibility may apply to the current investigation, previous research has shown that consumers believe that external stakeholders (namely, food manufacturers) need to take responsibility for reducing salt intake ${ }^{(5,17)}$; however, it is not known whether and how this may influence their support for various salt reduction policies. How motivated an individual is to make healthier choices has also been shown to impact support for various health policies ${ }^{(13,18)}$. Patel and colleagues $^{(15)}$ found that participants who reported more of a desire to eat a diet low in salt were also more likely to agree to government action to restrict salt content in foods. Another study found that individuals taking personal action to limit their salt intake were more likely to perceive certain barriers to reducing salt intake compared with those who were not taking personal action ${ }^{(16)}$. These barriers included a perceived lack of low-salt choices in shops and restaurants and a difficulty in understanding salt information on food labels. Thus, those motivated to make healthier food choices and to reduce their salt intake may be more supportive of government efforts that would make these behaviours easier for the consumer. Familiarity as a driver of policy support has also been suggested as a variable deserving of further research ${ }^{(4)}$. Research indicates that there is generally more support for an intervention that has already been implemented, possibly as a result of seeing its benefits materialise and/or the operation of the status quo bias $^{(14)}$. In line with the literature in this area ${ }^{(4)}$, the present study considers both sociodemographic factors and attitudes and beliefs as drivers of support for salt reduction policies. We also consider objective knowledge, which has been suggested as an important predictor of support for nutrition policies ${ }^{(4)}$, as a third driver. Specifically, we consider declarative salt knowledge, which relates to factual knowledge that one may have about intake of salt in the diet and its relationship to health ${ }^{(19)}$. It is common for educational campaigns to accompany salt reduction measures in the hope that a more knowledgeable public will be a more supportive public ${ }^{(20)}$.

\section{Materials and methods}

\section{Design and procedure}

A cross-sectional survey was carried out in November 2014 with a sample of 501 participants within the Republic 
of Ireland. Participants were recruited by a market research agency and invited to fill out an online questionnaire that took approximately $25 \mathrm{~min}$. A quota sampling procedure was employed with quota control variables of age, gender, region and social class. Participants were recruited from a national online research panel. Participants completed the study using their own electronic device (computer, mobile phone, etc.) within their own setting. Informed consent was provided by all participants and upon completion of the study, participants were provided with the names of national organisations' websites where they could find out more information on salt and health. The market research agency provided each participant with 'points' to the approximate value of $€ 5$ that could be reimbursed into vouchers. The study qualified for ethical exemption from the Research Ethics Committee at University College Dublin, Ireland. A pilot study was carried out with ten adults to ensure that the survey format, instructions and questions were easily comprehended and culturally suitable.

\section{Materials}

\section{Sociodemographic factors}

Standard demographic questions were included in the survey. For the analysis in the present study, age was recoded into six categories and education was recoded into a binary variable of education/training beyond secondary school and no education/training beyond secondary school. We also asked participants to rate how concerned they were about high blood pressure (hypertension). This was measured on a 5-point scale and treated as a continuous variable in the analysis for the current study, where higher scores indicated more concern. Participants were also asked whether or not they were following a low-salt diet (yes or no).

\section{Food choice motives: importance of health}

The Health Scale from the Food Choice Motives Questionnaire $^{(21)}$ was used to examine the importance of health in making food choices. Six items were rated on a 5-point Likert scale and an overall average score was calculated. Higher scores reflected that health was an important motivation in making food choices. We found excellent internal consistency $(\alpha=0 \cdot 90)$.

\section{Declarative salt knowledge}

Three separate questions, which are frequently employed in the literature ${ }^{(19)}$, were used to assess declarative salt knowledge. Participants were asked to identify the main source of salt in the Irish diet (choosing from four options, or 'don't know'), the maximum recommended daily salt intake for Irish adults (entered in grams per day, or 'don't know') and the relationship between salt and sodium (choosing from three options, or 'don't know'). Full wording of the questions is found in Table 2.
Familiarity with Irish national salt reduction programme To assess participants' awareness of the current salt reduction initiative in Ireland, we drew on the Consensus Action on Salt and Health ${ }^{(22)}$ survey that investigated consumer perceptions of salt and salt labelling in the UK, including a question which asked participants of their awareness of the Food Standards Agency initiative to reduce the salt intake of the UK population. We presented participants with a brief description of the Irish salt reduction programme, outlining the partnership approach between the food industry and various state bodies and organisations, and the long-term goal of reducing the average Irish population intake of salt to $6 \mathrm{~g} / \mathrm{d}$. Following this description, participants were asked whether they were aware of this salt reduction programme (yes or no). This question was presented after all other salt-related questions in the survey, and participants were not able to move backwards in the survey once they had reached this question.

\section{Interest in reducing salt intake}

We assessed participants' interest in engaging in salt reduction by employing a measure developed by Newson and colleagues ${ }^{(17)}$ that is based on the theoretical framework from the stages of change model ${ }^{(23)}$. Participants were asked to choose only the statement that best represented their current interest in reducing their salt intake (see Table 2 for full wording of these statements). For the analysis in the current paper, participants were divided into one of two categories based on their chosen answer: no interest in reducing salt intake (those selecting the first statement of 'no interest') or interest in reducing salt intake (those selecting any of the four remaining statements).

\section{Attributions of responsibility for salt reduction}

We employed a previously developed 'responsibility for salt reduction' scale by Newson and colleagues ${ }^{(17)}$ to assess how much responsibility participants felt different groups of stakeholders had for reducing salt intake in the population. Participants were asked to rate how much of the responsibility for reducing salt intake should lie with each of seven groups (see Table 3 for full list). Attributions of responsibility were scored on a scale of 1 ('not at all responsible') to 7 ('completely responsible').

\section{Support for government-led salt reduction policies}

Participants were asked to rate the level of importance that they felt the Irish government should assign to thirteen different salt reduction policies. The assessed policies spanned government-industry cooperation, educational measures, restrictions on salt content of foods, labelling and fiscal measures. The items representing the thirteen policies were adapted from research carried out with a Canadian population ${ }^{(16,24)}$. Each item was scored on a scale of 1 ('not at all important') to 5 ('extremely important'). The order of presentation of the items was randomised 
across the sample to reduce any possible bias that may arise from respondent fatigue. The full wording of the items is found in Table 4.

\section{Statistical analyses}

All analyses were conducted on weighted data using the statistical software package IBM SPSS Statistics 20·0. The data were weighted to represent the Irish population in terms of gender, age, social class and region. Mean scores and standard deviations along with frequency distributions for key variables of interest are presented in table format. A series of multiple linear regressions was carried out using a backward stepwise method to predict public support for thirteen different salt reduction policies. Selection of variables for model building was based on previous literature. In the current study we included the following predictors in the model: sociodemographic factors (age, gender, education, blood pressure concerns and low-salt diet), declarative salt knowledge, and attitudes and beliefs (attributed responsibility for salt reduction; interest in reducing salt intake; health motivations in food choice; familiarity of national salt reduction programme). Multicollinearity was checked during model building. The variance inflation factor scores in the analyses were all less than 10 and the correlation matrix indicated that all correlations between the predictor variables were low, with one exception. Attributions of responsibility for international organisations and attributions of responsibility for the national government were highly correlated $(r=0.75)$; given our focus on national government-led policies, we were most interested in attributions relating to the national government so we retained this variable in the analysis and omitted attributions of responsibility of international organisations from further analysis.

\section{Results}

\section{Salt knowledge and beliefs}

Sample characteristics are provided in Table 1 . Table 2 shows declarative salt knowledge and salt beliefs for the overall sample. There appeared to be sufficient levels of salt knowledge among many participants but considerable deficits were also recorded. Table 3 shows how participants rated responsibility for reducing salt intake in the Irish population. Consumers rated themselves as having the most responsibility, with the food sector also viewed as having a significant role.

\section{Public support for government-led salt reduction policies}

Table 4 shows the support among participants for a range of salt reduction policies; it shows majority support for all of the proposed initiatives, although lower rates of support
Table 1 Characteristics of the sample of Irish consumers ( $n 501)$, November 2014

\begin{tabular}{|c|c|c|}
\hline Characteristic & $n$ & $\%$ \\
\hline \multicolumn{3}{|l|}{ Age (years) } \\
\hline $18-24$ & 76 & $15 \cdot 2$ \\
\hline $25-34$ & 115 & 23.0 \\
\hline $35-44$ & 95 & $19 \cdot 0$ \\
\hline $45-54$ & 80 & $16 \cdot 0$ \\
\hline $55-64$ & 88 & $17 \cdot 6$ \\
\hline $65+$ & 47 & 9.4 \\
\hline \multicolumn{3}{|l|}{ Gender } \\
\hline Male & 238 & 47.5 \\
\hline Female & 263 & 52.5 \\
\hline \multicolumn{3}{|l|}{ Region of residence } \\
\hline Dublin & 146 & 29.1 \\
\hline Leinster (excluding Dublin) & 128 & $25 \cdot 5$ \\
\hline Munster & 143 & 28.5 \\
\hline Connaught and Ulster & 84 & $16 \cdot 8$ \\
\hline \multicolumn{3}{|l|}{ Marital status } \\
\hline Married & 249 & $49 \cdot 7$ \\
\hline Living together & 69 & 13.8 \\
\hline Single - never married & 140 & 27.9 \\
\hline Divorced & 18 & 3.6 \\
\hline Widowed & 8 & 1.6 \\
\hline Separated & 17 & 3.4 \\
\hline Parent/guardian of children under 17 years & 168 & 33.5 \\
\hline \multicolumn{3}{|l|}{ Employment status } \\
\hline Work full-time or self-employed & 179 & $35 \cdot 7$ \\
\hline Work part-time or self-employed & 82 & $16 \cdot 4$ \\
\hline Student & 65 & $13 \cdot 0$ \\
\hline Housewife & 49 & 9.8 \\
\hline Retired & 62 & $12 \cdot 4$ \\
\hline Full-time carer & 5 & 1.0 \\
\hline Unemployed & 59 & 11.8 \\
\hline \multicolumn{3}{|l|}{ Education status } \\
\hline Some primary education (not complete) & 2 & 0.4 \\
\hline Primary or equivalent & 12 & 2.4 \\
\hline Intermediate/junior/group certificate or equivalent & 36 & $7 \cdot 2$ \\
\hline Leaving certificate or equivalent* & 151 & $30 \cdot 1$ \\
\hline Diploma/certificate & 100 & $20 \cdot 0$ \\
\hline Apprenticeship/trade certificate/FAS training $\dagger$ & 26 & $5 \cdot 2$ \\
\hline Primary degree/nursing qualification & 80 & $16 \cdot 0$ \\
\hline Postgraduate/higher degree & 91 & $18 \cdot 2$ \\
\hline Other & 3 & 0.6 \\
\hline Following a low-salt diet & 177 & $35 \cdot 3$ \\
\hline \multicolumn{3}{|l|}{ Concerned about hypertension (high blood pressure) } \\
\hline Not at all & 64 & $12 \cdot 8$ \\
\hline Slightly & 98 & 19.6 \\
\hline Somewhat & 97 & $19 \cdot 4$ \\
\hline Moderately & 122 & 24.4 \\
\hline Extremely & 120 & $24 \cdot 0$ \\
\hline
\end{tabular}

*Second-level education in Ireland consists of a junior cycle (intermediate/ junior/group certificate) and a senior cycle (leaving certificate).

tFAS training refers to training courses available within Ireland suited to the needs of jobseekers looking for employment.

were recorded for the two suggested fiscal measures (subsidising low-salt foods and taxing high-salt foods). A voluntary approach between government and industry was viewed as the most important initiative (79.7\%), with the education initiatives garnering support of between $\mathbf{7 7 . 6}$ and $79.4 \%$. Restrictions on the salt content of foods aimed at children and vulnerable people were also strongly supported (75-78\%), with just slightly less support for restrictions on the salt content of processed foods sold in stores $(71.9 \%)$. Front-of-pack labelling initiatives were strongly supported (79.0\%), although menu labelling in restaurants received less support (67.2\%). The least support 
Table 2 Declarative salt knowledge and salt beliefs among the sample of Irish consumers ( $n$ 501), November 2014

\begin{tabular}{|c|c|c|}
\hline & $n$ & $\%$ \\
\hline \multicolumn{3}{|l|}{ Which of the following do you think is the main source of salt in the diet of Irish people? } \\
\hline Salt added during preparation or cooking at home & 63 & $12 \cdot 6$ \\
\hline Salt added at the table & 111 & $22 \cdot 2$ \\
\hline Salt in processed foods such as breads, breakfast cereals, tinned foods, ready meals and takeaways & 324 & 64.7 \\
\hline Salt in restaurant foods & 1 & 0.2 \\
\hline Don't know & 2 & 0.4 \\
\hline \multicolumn{3}{|l|}{ Which of the following statements best describes the relationship between salt and sodium? } \\
\hline They are exactly the same & 174 & 34.7 \\
\hline Salt contains sodium & 221 & $44 \cdot 1$ \\
\hline Sodium contains salt & 29 & $5 \cdot 8$ \\
\hline Don’t know & 77 & 15.4 \\
\hline \multicolumn{3}{|l|}{ What is the maximum level of salt per day that a healthy Irish adult is recommended to consume? } \\
\hline $0-2 \mathrm{~g}$ & 94 & $18 \cdot 8$ \\
\hline $3-5 \mathrm{~g}$ & 120 & $24 \cdot 0$ \\
\hline $6 \mathrm{~g}$ & 50 & $10 \cdot 0$ \\
\hline $7-9 \mathrm{~g}$ & 10 & $2 \cdot 0$ \\
\hline $10-19 \mathrm{~g}$ & 37 & 7.4 \\
\hline $20+g$ & 49 & $9 \cdot 8$ \\
\hline Don’t know & 141 & $28 \cdot 1$ \\
\hline \multicolumn{3}{|l|}{ Awareness of Irish salt reduction programme } \\
\hline Yes & 59 & $11 \cdot 8$ \\
\hline No & 441 & 88.2 \\
\hline \multicolumn{3}{|l|}{ Interest in reducing salt intake } \\
\hline $\begin{array}{l}\text { I am not at all interested in lowering salt in my diet and I have no intention of doing so in the next } 6 \text { months } \\
\text { I am interested in lowering salt in my diet and... }\end{array}$ & 119 & $23 \cdot 8$ \\
\hline$\ldots I$ have the intention of doing that within the next 6 months & 131 & $26 \cdot 2$ \\
\hline$\ldots I$ have the intention of doing that within the next month & 57 & $11 \cdot 3$ \\
\hline$\ldots I$ have started lowering my salt intake during the last 6 months & 57 & $11 \cdot 3$ \\
\hline$\ldots I$ have already lowered my salt intake for longer than 6 months & 137 & 27.4 \\
\hline
\end{tabular}

Table 3 Level of perceived responsibility for reducing population salt intake among the sample of Irish consumers ( $n$ 501), November 2014

\begin{tabular}{lcc}
\hline & Mean & SD \\
\hline Yourself & 6.15 & 1.28 \\
Food manufacturers & 5.73 & 1.37 \\
Restaurants/fast-food chains/caterers & 5.26 & 1.49 \\
Friends and family & 4.74 & 1.85 \\
Business (e.g. supermarkets, local shops, markets) & 4.52 & 1.66 \\
The national government & 4.43 & 1.71 \\
International organisations & 4.07 & 1.75 \\
\hline
\end{tabular}

was evident for the two fiscal policies, with subsidisation of low-salt foods receiving $56.6 \%$ support and a proposed tax of high-salt foods receiving only $42 \cdot 2 \%$ support.

\section{Predicting public support for government-led salt reduction policies}

The overall regression models for all of the salt reduction policies were statistically significant in predicting public support. The final models explained between $14 \%$ (taxing high-salt foods) and $35 \%$ (restrictions on salt content of processed foods sold in stores) of policy support. The standardised coefficients of the model for each salt reduction policy allow us to compare the impact of the different explanatory factors and are reported in Table 5.

Sociodemographic factors did not emerge as strong predictors. Females were more likely to support four of the policies: public education on nutrition labelling, mandatory front-of-pack labelling, and salt restrictions in foods served in child-care centres/schools and in foods marketed at children in restaurants. Age emerged as a significant predictor of support, where older participants were more likely to support a voluntary approach between government and the food industry, and younger participants were more likely to support subsidisation of low-salt foods. Participants who received education/training after postprimary were more likely to support education efforts on the dangers of salt in the diet. With regard to lifestyle factors, following a low-salt diet led to more support for mandatory labelling on both high-salt foods and restaurant menus. The more concerned a participant was about hypertension, the more supportive he/she was of education measures, mandatory front-of-pack labelling and subsidising low-salt foods. With regard to declarative salt knowledge, having the correct knowledge that processed foods are the largest source of sodium in the diet led to more support for a number of the policies, although the other knowledge variables had little predictive value.

Attitudinal drivers were the most influential predictors in the models. Participants who placed the most importance on health in making food choices were more supportive of all of the salt reduction policies. Interest in reducing one's salt intake predicted greater support for almost all of the policies. Attributions of responsibility for salt reduction in society also emerged as an influential predictor in these models. There was greater support for almost all of the 
Table 4 Level of importance that the national government should assign to thirteen different salt reduction policies according to the sample of Irish consumers ( $n$ 501), November 2014

\begin{tabular}{|c|c|c|c|c|c|}
\hline & $\begin{array}{c}\text { Extremely } \\
\text { important } \\
(\%)\end{array}$ & $\begin{array}{c}\text { Moderately } \\
\text { important } \\
(\%)\end{array}$ & $\begin{array}{l}\text { Neutral } \\
(\%)\end{array}$ & $\begin{array}{l}\text { Slightly } \\
\text { important } \\
(\%)\end{array}$ & $\begin{array}{c}\text { Not at all } \\
\text { important } \\
(\%)\end{array}$ \\
\hline \multicolumn{6}{|l|}{ Government-industry cooperation } \\
\hline $\begin{array}{l}\text { The national government and the food industry should work together to } \\
\text { reduce salt levels in processed foods }\end{array}$ & $56 \cdot 9$ & $22 \cdot 8$ & $11 \cdot 8$ & $7 \cdot 0$ & 1.6 \\
\hline \multicolumn{6}{|l|}{ Education: The national government should educate consumers about... } \\
\hline ...the dangers of too much salt in the diet & $50 \cdot 1$ & $29 \cdot 3$ & 14.4 & $5 \cdot 2$ & 1.0 \\
\hline ...how to make lower salt choices & $45 \cdot 7$ & 32.5 & 14.6 & $5 \cdot \overline{8}$ & 1.4 \\
\hline ...how to read nutrition labels & 47.9 & $29 \cdot 7$ & $15 \cdot 0$ & $5 \cdot 6$ & 1.8 \\
\hline \multicolumn{6}{|c|}{ Restrictions on salt content of foods: The national government should set a maximum amount of salt... } \\
\hline ...in processed foods that are marketed to children in grocery stores & $55 \cdot 1$ & $22 \cdot 6$ & 13.8 & $6 \cdot 6$ & $2 \cdot 0$ \\
\hline ....in foods served in child-care centres and schools & $55 \cdot 1$ & 22.4 & 13.8 & $6 \cdot 6$ & $2 \cdot 2$ \\
\hline .... in foods served in hospitals and nursing homes & $52 \cdot 5$ & 23.6 & $15 \cdot 8$ & 6.4 & 1.8 \\
\hline ....in foods that are marketed to children in restaurants & $50 \cdot 1$ & $25 \cdot 3$ & $15 \cdot 0$ & $6 \cdot 2$ & 3.4 \\
\hline ...that can be added to processed foods sold in grocery stores & $50 \cdot 7$ & $21 \cdot 2$ & $17 \cdot 0$ & 8.0 & 3.2 \\
\hline \multicolumn{6}{|l|}{ Labelling: The national government should require... } \\
\hline $\begin{array}{l}\text {...that foods that are high in salt will have to display a warning label, } \\
\text { statement or symbol on the front of the package }\end{array}$ & $52 \cdot 1$ & $26 \cdot 9$ & $13 \cdot 2$ & $5 \cdot 6$ & $2 \cdot 2$ \\
\hline $\begin{array}{l}\text {....restaurants to display the amount of salt in the foods they serve } \\
\text { Fiscal measures }\end{array}$ & 38.9 & $28 \cdot 3$ & $21 \cdot 2$ & $6 \cdot 8$ & 4.8 \\
\hline Foods lower in salt should be subsidised (thus making them cheaper to buy) & $30 \cdot 1$ & $26 \cdot 5$ & 28.7 & $7 \cdot 2$ & $7 \cdot 4$ \\
\hline High-salt foods should be taxed (thus making them more expensive to buy) & $20 \cdot 6$ & 21.6 & $30 \cdot 3$ & 11.6 & $16 \cdot 0$ \\
\hline
\end{tabular}

policies when participants attributed greater responsibility for salt reduction to food manufacturers and the national government. There were two exceptions in this regard: attributions of responsibility towards food manufacturers did not predict support for taxing high-salt foods and attributions of responsibility towards the national government did not predict support for subsidising low-salt foods. When participants perceived themselves to be more responsible for reducing salt intake, they were more likely to support education on lower-salt choices and salt restrictions on foods targeted at vulnerable consumers. When business (supermarkets, local shops, markets) was viewed to be more responsible for reducing salt intake, there was more support for subsidising low-salt foods and taxing high-salt foods, but less support for governmentindustry cooperation, salt restrictions in foods served in schools and child-care centres, education on the dangers of salt in the diet and mandatory salt labelling on menus. When restaurants/fast-food chains/caterers were viewed to be more responsible for reducing salt intake, there was less support for taxing high-salt foods but there was greater support for labelling on menus, restricting salt content in foods directed at children in restaurants and in foods served in child-care centres and schools, and government-industry cooperation.

\section{Discussion}

The current study found majority support among participants for a range of government-led policies to reduce population salt intake in Ireland. Only the two proposed fiscal measures received low levels of support. Among the predictors investigated, attitudes and beliefs explained more of the variance in support than sociodemographic factors, lifestyle or knowledge. The study reveals important differences in support for various government actions on salt reduction, which should be considered when taking action on salt in the future. Our findings also provide important knowledge on predictors of support that may be used to better target and implement salt reduction policies to meet the needs of a diverse public.

Voluntary collaborations between government and the food industry, regulated salt restrictions in different settings, and food package labelling all received quite high levels of support, with only subtle differences in support levels across these policies. The high levels of support found for these particular salt reduction policies is consistent with a previous study in Canada ${ }^{(16)}$. It is worth highlighting that menu labelling of salt in restaurants, although supported by the majority, had slightly lower levels of support in comparison. Heery and colleagues ${ }^{(14)}$ investigated attitudes of Irish consumers towards obesity prevention policies and, in comparison to the current study, found slightly higher levels of support among their sample for calorie and nutrient labelling on menus. There has been some attention given to menu labelling as a healthy eating policy within Ireland; a voluntary scheme is currently in place whereby food businesses in Ireland are encouraged to put calories on menus and are provided with technical guidance to do so ${ }^{(25)}$. The two fiscal policies (subsidising low-salt foods and taxing high-salt foods) received the least support, with a majority opposed to a tax on high-salt foods. That the public is less likely to prefer intrusive or personally restrictive policies is in line with previous studies ${ }^{(13,15)}$. However, it is suggested that 
Table 5 Standardised coefficients for predictors entered into the model for each salt reduction policy ( $n$ 497)

\begin{tabular}{|c|c|c|c|c|c|c|c|c|c|c|c|c|c|}
\hline Predictor & $\begin{array}{l}\text { Government- } \\
\text { industry } \\
\text { cooperation }\end{array}$ & $\begin{array}{l}\text { Salt } \\
\text { restrictions: } \\
\text { foods sold } \\
\text { in grocery } \\
\text { stores }\end{array}$ & $\begin{array}{l}\text { Salt } \\
\text { restrictions: } \\
\text { foods } \\
\text { marketed to } \\
\text { children in } \\
\text { grocery } \\
\text { stores }\end{array}$ & $\begin{array}{l}\text { Salt } \\
\text { restrictions: } \\
\text { foods } \\
\text { marketed to } \\
\text { children in } \\
\text { restaurants }\end{array}$ & $\begin{array}{l}\text { Salt } \\
\text { restrictions: } \\
\text { foods } \\
\text { served in } \\
\text { child-care } \\
\text { centres and } \\
\text { schools }\end{array}$ & $\begin{array}{l}\text { Salt } \\
\text { restrictions: } \\
\text { foods } \\
\text { served in } \\
\text { hospitals } \\
\text { and nursing } \\
\text { homes }\end{array}$ & $\begin{array}{l}\text { Education: } \\
\text { dangers of } \\
\text { salt in diet }\end{array}$ & $\begin{array}{l}\text { Education: } \\
\text { reading } \\
\text { labels }\end{array}$ & $\begin{array}{l}\text { Education: } \\
\text { lower-salt } \\
\text { choices }\end{array}$ & $\begin{array}{l}\text { Labelling: } \\
\text { menus }\end{array}$ & $\begin{array}{l}\text { Labelling: } \\
\text { front-of- } \\
\text { pack }\end{array}$ & $\begin{array}{l}\text { Subsidise } \\
\text { low-salt } \\
\text { foods }\end{array}$ & $\begin{array}{l}\text { Tax high- } \\
\text { salt foods }\end{array}$ \\
\hline \multicolumn{14}{|c|}{ Sociodemographic factors and lifestyle } \\
\hline Female (relative to male) & & & & $0.08^{\star}$ & $0.09^{*}$ & & & $0.08^{*}$ & & & $0.10^{*}$ & & \\
\hline $\begin{array}{l}\text { Age in years } \\
\text { Education/training beyond } \\
\text { secondary school } \\
\text { (relative to none) }\end{array}$ & $0 \cdot 13^{\star \star}$ & & & & 0.07 & & $\begin{array}{l}0.08 \\
0.08^{\star}\end{array}$ & & 0.07 & & & $\begin{array}{l}-0.19^{\star \star \star} \\
-0.07\end{array}$ & \\
\hline $\begin{array}{l}\text { Personal health concerns: } \\
\text { hypertension }\end{array}$ & & & & & & & & $0.09^{*}$ & $0.09^{*}$ & & $0.09^{*}$ & $0.09^{*}$ & \\
\hline $\begin{array}{l}\text { Following a low-salt diet } \\
\text { (relative to not following) }\end{array}$ & & 0.08 & & 0.08 & & & & 0.07 & 0.07 & $0.11^{* *}$ & $0.11^{\star *}$ & 0.09 & \\
\hline \multicolumn{14}{|l|}{ Knowledge } \\
\hline $\begin{array}{l}\text { Knowledge of main source } \\
\text { of salt in the diet (relative } \\
\text { to incorrect or don't know) }\end{array}$ & $0.12^{\star *}$ & $0 \cdot 10^{\star *}$ & & & $0 \cdot 10^{\star \star \star}$ & $0.08^{\star}$ & & & 0.07 & $0.08^{\star}$ & $0 \cdot 10^{* *}$ & & \\
\hline $\begin{array}{l}\text { Knowledge of sodium-salt } \\
\text { relationship (relative to } \\
\text { incorrect or don't know) }\end{array}$ & & & & & & & & & & & -0.06 & & \\
\hline $\begin{array}{l}\text { Knowledge of } \\
\text { recommended daily } \\
\text { intake of salt (relative to } \\
\text { incorrect or don't know) }\end{array}$ & & & & & & & & & & & & $-0 \cdot 11^{* *}$ & \\
\hline \multicolumn{14}{|l|}{ Attitudes and beliefs } \\
\hline $\begin{array}{l}\text { Health motivations in food } \\
\text { choice }\end{array}$ & $0.20^{\star \star \star}$ & $0.25^{\star \star \star}$ & $0.26^{\star \star \star}$ & $0.22^{\star \star \star}$ & $0.18^{\star \star \star}$ & $0.23^{\star \star \star}$ & $0.24^{\star \star *}$ & $0.25^{\star \star \star}$ & $0.22^{\star \star \star}$ & $0 \cdot 24^{\star \star \star}$ & $0.20^{\star \star \star}$ & $0 \cdot 21^{\star \star \star}$ & $0 \cdot 18^{\star \star \star}$ \\
\hline $\begin{array}{l}\text { Interest in reducing salt } \\
\text { intake (relative to no } \\
\text { interest) }\end{array}$ & 0.07 & $0.09^{*}$ & $0 \cdot 12^{* *}$ & $0.09^{*}$ & $0 \cdot 12^{\star *}$ & $0 \cdot 13^{* *}$ & $0.09^{*}$ & & 0.07 & $0 \cdot 10^{*}$ & & 0.08 & $0 \cdot 16^{\star \star *}$ \\
\hline $\begin{array}{l}\text { Attribution of responsibility: } \\
\text { yourself }\end{array}$ & & 0.07 & & $0.09^{*}$ & $0.15^{\star \star \star}$ & $0 \cdot 14^{* *}$ & 0.07 & & $0.09^{\star}$ & & 0.07 & & \\
\hline $\begin{array}{l}\text { Attribution of responsibility: } \\
\text { food manufacturers }\end{array}$ & $0.21^{\star \star \star}$ & $0.27^{\star \star \star}$ & $0.28^{\star \star *}$ & $0.17^{\star \star}$ & $0 \cdot 18^{\star \star}$ & $0.22^{* \star *}$ & $0.17^{\star \star}$ & $0.19^{\star \star \star}$ & $0.11^{*}$ & $0.11^{*}$ & $0.22^{\star \star \star}$ & $0 \cdot 16^{\star *}$ & \\
\hline $\begin{array}{l}\text { Attribution of responsibility: } \\
\text { national government }\end{array}$ & $0.22^{\star \star \star}$ & $0 \cdot 18^{\star \star \star}$ & $0 \cdot 15^{\star *}$ & $0.14^{\star \star}$ & $0.21^{\star \star *}$ & $0 \cdot 10^{*}$ & $0.20^{\star \star \star}$ & $0.18^{\star \star \star}$ & $0.17^{\star * *}$ & $0.21^{\star \star \star}$ & $0 \cdot 15^{\star \star}$ & & $0 \cdot 18^{\star \star}$ \\
\hline $\begin{array}{l}\text { Attribution of responsibility: } \\
\text { business }\end{array}$ & $-0 \cdot 16^{* *}$ & & & & $-0.11^{*}$ & & $-0 \cdot 15^{*}$ & & & $-0.11^{*}$ & & $0.10^{*}$ & $0.15^{*}$ \\
\hline $\begin{array}{l}\text { Attribution of responsibility: } \\
\text { restaurants, etc. }\end{array}$ & $0.15^{\star \star}$ & & & $0 \cdot 18^{\star *}$ & $0.15^{\star \star}$ & & 0.11 & & & $0.17^{\star *}$ & & & $-0.14^{*}$ \\
\hline $\begin{array}{l}\text { Attribution of responsibility: } \\
\text { friends and family }\end{array}$ & & $-0.09^{*}$ & & $-0.14^{\star \star}$ & -0.09 & & & & & & & & \\
\hline $\begin{array}{l}\text { Aware of salt programme } \\
\text { (relative to unaware) } \\
\text { Model statistics }\end{array}$ & & & -0.07 & & & & & & & & & -0.07 & \\
\hline $\begin{array}{l}\text { Model statistics } \\
R^{2}\end{array}$ & 0.31 & 0.35 & 0.30 & 0.30 & 0.33 & 0.28 & 0.27 & 0.27 & 0.25 & 0.29 & 0.32 & 0.20 & 0.14 \\
\hline$F$ & $26 \cdot 92^{\star \star \star}$ & $32 \cdot 69^{\star \star *}$ & $42 \cdot 62^{\star \star \star}$ & $23.53^{\star \star \star}$ & $21 \cdot 63^{\star \star \star}$ & $32 \cdot 27^{\star \star \star}$ & $19 \cdot 99^{* \star *}$ & $29 \cdot 93^{\star \star \star}$ & $18 \cdot 40^{\star \star \star}$ & 24.62 & $25 \cdot 80^{\star \star \star}$ & $12 \cdot 33^{\star \star \star}$ & $16 \cdot 46^{\star \star \star}$ \\
\hline
\end{tabular}

Note: empty cells indicate that this variable was not included in the final model for that salt reduction policy.

${ }^{*} P<0.05,{ }^{* *} P<0.01,{ }^{* * *} P<0.001$. 
acceptability can be increased by framing the outcomes of an intervention to address issues of fairness ${ }^{(12,13)}$. For example, assuring individuals of how taxes are going to be used to their benefit may help to alleviate concerns associated with fairness. This is thought to have been the case in the study by Heery et al. ${ }^{(14)}$, who found higher support for taxing unhealthy foods when it was stated that taxes collected would be used to promote healthy eating. Worldwide, population targets for salt intake have proved difficult to meet, and Ireland is no different. To ensure that targets are met, there have been calls for a more regulated approach to the food industry's reformulation efforts, with some suggesting that mandatory national standards for salt content should be phased in ${ }^{(10)}$. This would be viewed as a more intrusive policy, but it is known that more restrictive policies are also often more effective ${ }^{(13)}$. Often policy makers and politicians are faced with a lack of public support for a policy option that stands the most chance of success, and thus they can be reluctant to implement such a policy for fear of political unpopularity and repercussions. In the current study we observed the lowest level of support for what was arguably the most restrictive policy: imposing taxes on high-salt food. At the same time, we observed high levels of support among the participants for other policies that would impose restrictions on personal choice, including regulated reformulation of food products across a number of different settings including shops and restaurants. The current findings may be of interest to policy makers in predicting public sentiment for future policies that could help ensure that the target of $6 \mathrm{~g}$ salt/d is met within Ireland.

Salt reduction is particularly promoted among older individuals and people with hypertension ${ }^{(9)}$. We found some evidence of greater support for some of the policies among older participants and those who were more concerned about hypertension; however, we did not identify very strong effects. This could be due to our inclusion of a variable within the regression analyses which independently captured interest in reducing salt intake (and which strongly predicted support). We found that those who were currently following a low-salt diet were more supportive of labelling on high-salt foods and on menus in restaurants. This is interesting in light of a previous study which found that a barrier encountered by individuals taking personal action to limit their salt intake was a difficulty in understanding salt information on food labels ${ }^{(16)}$. The current labelling of salt content in foods may not be sufficient to meet the needs of those currently taking action to reduce their salt intake. Overall, sociodemographic factors, lifestyle and knowledge failed to emerge as strong predictors for support of salt reduction policies - this is consistent with the literature in the broader area ${ }^{(4,14)}$ and supports the theory that such characteristics do not play a major role in determining public support of healthy eating policies; rather, beliefs and attitudes appear to be what heavily influence support.
Participants who were motivated to make healthy food choices and reduce their intake of salt were more likely to support government action which removes barriers and helps assist them in doing that, in line with previous research $^{(16)}$. This finding highlights the importance of policies aimed at the individual level to encourage the development of healthy eating beliefs among the public, and to motivate the public to at least want to make healthier food choices. While health education and promotion campaigns may prove difficult in changing actual behaviour, they may have an effect of increasing public support for more intrusive initiatives that may be necessary to achieve optimal health outcomes ${ }^{(20)}$. Declarative salt knowledge did not emerge as a strong predictor of support in our study; thus care is needed in how health promotion campaigns are framed and what is hoped to be achieved from such campaigns (e.g. targeting one's beliefs and attitudes rather than trying to improve one's knowledge). The only knowledge variable to emerge as a significant predictor related to accurately identifying that the main source of salt was from processed foods, with those answering this question correctly reporting greater support for a number of the salt restriction policies and the food labelling policies - policies that would directly involve processed foods. Thus, this effect may have had more to do with causal beliefs about what or who is responsible for large amounts of salt in the population diet, and less to do with having a good level of declarative knowledge relating to salt. In support of this, attributions of responsibility to third parties for salt reduction emerged as strong predictors of support. Attributions of responsibility to oneself were not as consistent a predictor. This complements previous findings that when third parties are viewed to be responsible for food and health-related issues, there is greater acceptance of government-led nutrition policies ${ }^{(12)}$.

Our study was not nationally representative of the Irish population, although we did aim to achieve a stratified sample based on age group, gender and region, and data were weighted based on gender, age, class and region. However, as this was an online survey, it is possible that we are missing the views of an important demographic, particularly those in the lower socio-economic groups and older age groups - both key target demographic groups for dietary behaviour policies. It is also worth bearing in mind the potentially transient nature of stated support for policies. Diepeveen and colleagues ${ }^{(13)}$ made an important point that where more restrictive policies target particular stakeholders (e.g. the food industry), then countercampaigns are invariably initiated and it is yet to be fully understood what impact these competing messages have on public opinion, and whether public opinion can be easily swayed in the presence of such societal debate. Further research is needed to investigate the stability and longevity of an individual's support for salt reduction policies. Some of our models explained only a small 
proportion of the variance in support, particularly for the fiscal policies. That said, our models are an improvement upon those that have previously included only sociodemographic predictors ${ }^{(14)}$.

\section{Conclusion}

The current study fills a gap by investigating the current level of support, and the multidimensional drivers of support, among the public for various salt reduction policies $^{(12)}$. The assessment of public support for health policies should be ingrained in the policy development process ${ }^{(26)}$. Our study provides stakeholders at the helm of public policy in Ireland with important information on current consumer sentiment towards ongoing and potential government actions related to salt reduction. A large number of our participants were in favour of the proposed salt reduction policies, and we also found that perceptual and attitudinal drivers accounted for some of the variance in support within the sample. Our study provides a knowledge base for policy makers in making decisions on future policy steps, and implementing those policies, to achieve the target population salt intake of $6 \mathrm{~g} / \mathrm{d}$ within Ireland.

\section{Acknowledgements}

Financial support: This research was funded by the Irish Government as part of the National Development Plan 2007-2013, under the Food Institutional Research Measure (FIRM) in the Department of Agriculture, Food and the Marine. The funder had no role in the design, analysis or writing of this article. Conflict of interest: None. Authorship: A.R. and A.Mc.C. designed the study. All authors contributed to methodological development. A.R. undertook data collection and analysis. C.L.S. and P.W. contributed to the analysis. A.R. drafted the manuscript, and all authors commented on it. Ethics of human subject participation: The study qualified for ethical exemption from the Research Ethics Committee at University College Dublin, Ireland.

\section{References}

1. Aburto NJ, Ziolkovska A, Hooper L et al. (2013) Effect of lower sodium intake on health: systematic review and metaanalyses. BMJ 346, f1326.

2. World Health Organization (2012) Effects of Reduced Sodium Intake on Cardiovascular Disease, Coronary Heart Disease and Stroke. Geneva: WHO.

3. World Health Organization (2008) WHO European Action Plan for Food and Nutrition Policy 2007-2012. Geneva: WHO

4. Mazzocchi M, Cagnone S, Bech-Larsen T et al. (2015) What is the public appetite for healthy eating policies? Evidence from a cross-European survey. Health Econ Policy Law 10, 267-292.

5. Kenten C, Boulay A \& Rowe G (2013) Salt. UK consumers' perceptions and consumption patterns. Appetite 70, 104-111.

6. Department of Health \& Children (2010) Changing Cardiovascular Health: National Cardiovascular Health Policy 2010-2019. Dublin: Government Publications.

7. O'Keefe C, Kabir Z, O'Flaherty M et al. (2013) Modelling the impact of specific food policy options on coronary heart disease and stroke deaths in Ireland. BMJ Open 3, e002837.

8. Webster JL, Trieu K, Dunford EK et al. (2014) Target Salt 2025: a global overview of national programs to encourage the food industry to reduce salt in foods. Nutrients $\mathbf{6}$, 3274-3287.

9. Food Safety Authority of Ireland (2005) Salt and Health: Review of the Scientific Evidence and Recommendations for Public Policy in Ireland. Dublin: FSAI.

10. Perry IJ, Browne D, Loughrey M et al. (2010) Dietary Salt Intake and Related Risk Factors in the Irish Population: A Report for Safefood. Dublin: Safefood.

11. Barron S, Balanda K, Hughes J et al. (2014) National and subnational hypertension prevalence estimates for the Republic of Ireland: better outcome and risk factor data are needed to produce better prevalence estimates. BMC Public Health 14, 24.

12. Bos C, Van der Lans I, Van Rijnsoever FJ et al. (2013) Understanding consumer acceptance of intervention strategies for healthy food choices: a qualitative study. $B M C$ Public Health 13, 1073.

13. Diepeveen S, Ling T, Suhrcke M et al. (2013) Public acceptability of government intervention to change healthrelated behaviours: a systematic review and narrative synthesis. BMC Public Health 13, 756.

14. Heery E, Delaney M, Kelleher C et al. (2014) Attitudes of the Irish Public Towards Policies to Address Obesity. Dublin: Safefood.

15. Patel SM, Gunn JP, Tong X et al. (2014) Consumer sentiment on actions reducing sodium in processed and restaurant foods, ConsumerStyles 2010. Am J Prev Med 46, 516-524.

16. Arcand J, Mendoza J, Qi Y et al. (2013) Results of a national survey examining Canadians' concern, actions, barriers, and support for dietary sodium reduction interventions. Can J Cardiol 29, 628-631.

17. Newson RS, Elmadfa I, Biro G et al. (2013) Barriers for progress in salt reduction in the general population. An international study. Appetite 71, 22-31.

18. Storvoll EE, Rossow I \& Rise J (2014) Changes in attitudes towards restrictive alcohol policy measures: the mediating role of changes in beliefs. J Subst Use 19, 38-43.

19. Sarmugam R \& Worsley A (2014) Current levels of salt knowledge: a review of the literature. Nutrients $\mathbf{6}, 5534-5559$.

20. Cobb LK, Appel LJ \& Anderson CAM (2012) Strategies to reduce dietary sodium intake. Curr Treat Options Cardiovasc Med 14, 425-434.

21. Steptoe A, Pollard TM \& Wardle J (1995) Development of a measure of the motives underlying the selection of food: the food choice questionnaire. Appetite 25, 267-284.

22. Consensus Action on Salt and Health (2003) Salt Survey in Adults. London: CASH.

23. Prochaska JO \& Velicer WF (1997) The transtheoretical model of health behaviour change. Am J Health Promot 12, $38-48$.

24. Health Canada (2009) Canadians' and Health Care Professionals' Views on Sodium. Ottawa: Health Canada.

25. Food Safety Authority of Ireland (2012) Calories on Menus in Ireland. Report on a National Consultation. Dublin: FSAI.

26. Hope A (2014) The ebb and flow of attitudes and policies on alcohol in Ireland 2002-2010. Drug Alcohol Rev 33, 235-241. 